\title{
Acht Tage, sieben Kräutlein! \\ Das Grüne Soße Festival 2011 auf dem Roßmarkt in Frankfurt am Main
}

\author{
Lolita Sebastian
}

Der Palmengarten wurde Anfang März 2011 dazu eingeladen, während des einwöchigen Festivals rund um die Frankfurter Grüne Soße in der Innenstadt mit einem Stand präsent zu sein.

Um den Stand für Besucherinnen und Besucher besonders interessant zu gestalten, sollte eine Mitmach-Aktion angeboten werden. Die Idee „Pflanze das eigene Kräutertöpfchen“ war schnell geboren. Dank der Übernahme von Personal- und Materialkosten durch die Palmengarten-Gesellschaft konnte dieses Projekt realisiert werden.

Theorie und Praxis sollten am Stand miteinander kombiniert und dabei die sieben planzli- chen Zutaten der Grünen Soße erklärt werden. Die Gärtnerei übernahm in ihren Gewächshäusern freundlicherweise die Aussaat und das Heranziehen der benötigten Kräuter Schnittlauch, Pimpinelle, Petersilie, Kerbel, Sauerampfer und Borretsch. Da Kresse andere Kulturbedingungen als die übrigen Kräuter benötigt, wurde auf sie verzichtet.

Festival-Start war am 21. Mai 2011. Der Palmengarten-Stand war mit reichlich Blumentöpfen, Pflanzerde und den entsprechenden Pflanzen ausgerüstet. Zusammen mit zwei Mitarbeiterinnen der Grünen Schule betreuten von Seiten der Palmengarten-Gesellschaft Lolita

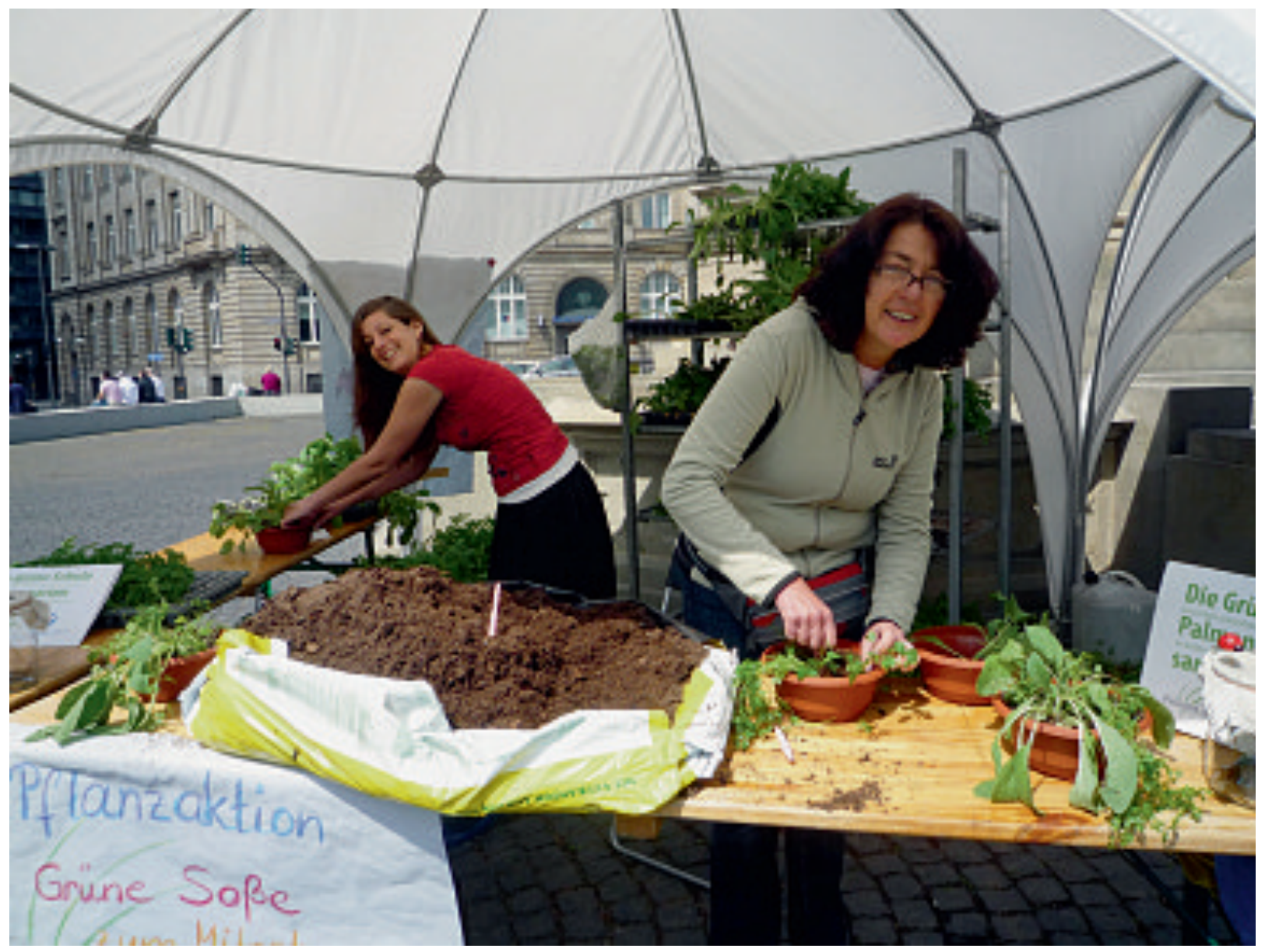




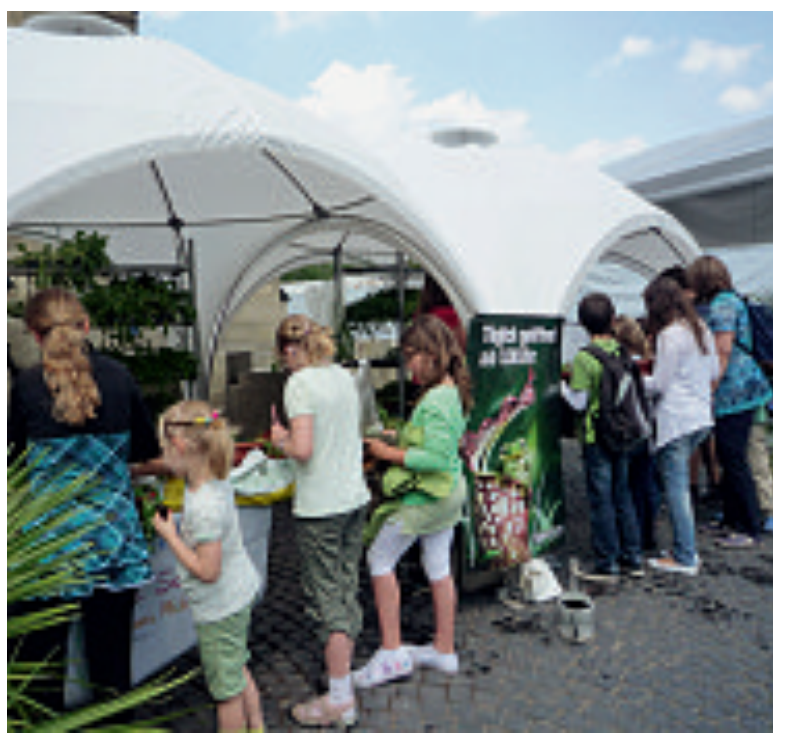

Sebastian und Herbert Billensteiner täglich den Stand von 10-20 Uhr: Es wurden Pflanzen getopft, gärtnerisch-botanische Auskünfte gegeben und konnte dabei gleichzeitig auf den Palmengarten und die Palmengarten-Gesellschaft hingewiesen werden. Plakate für die kommende Rosenschau und die gerade eröffnete Informationsausstellung „Tausend und ein Öl“ machten zudem auf Aktivitäten im Palmengarten aufmerksam. Und immer wieder tauchten Fragen auf wie „Wie überwintere ich eine Palme?“, „Was mache ich gegen Blattläuse?" oder „Dürfen die Kräuter blühen, wenn ich sie für die Grüne Soße ernten will?"“.

Die zarten Pflänzchen lockten viele Besucher an, es wurde probiert, geraten, gefachsimpelt und gepflanzt. Groß und Klein trugen ihre Töpfchen mit den sechs Kräutern glücklich heim, wobei manch ein Topf vorher noch schnell in die Oper oder das Volkstheater musste. Sogar eine Königin besuchte uns mit ihrem Gefolge, nämlich die Büdesheimer Laternenkönigin Sandra II. Groß war die Freude von zufällig vorbeikommenden Mitgliedern der Palmen-

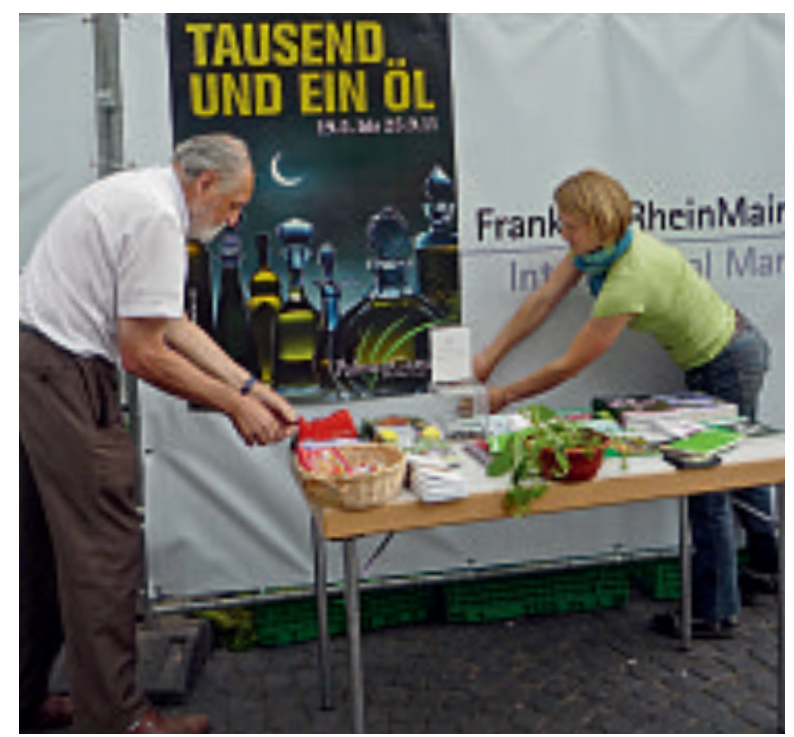

garten-Gesellschaft, die von der Präsenz des Palmengartens auf dem Festival positiv überrascht waren.

Am letzten Tag (28. Mai) war ganz besonders viel los. Mittags kamen Schülerinnen und Schüler zur Prämierung der von ihnen zubereiteten ,Grie Soß`. Jetzt gingen massenweise Pflanztöpfe über den Tisch. Bis zum Abend wurde mit großem Eifer eingetopft, gegossen und über Rezepte geplaudert.

Gegen 19.30 Uhr klang das Festival aus. Für die Standbetreuer war es zwar eine anstrengende Woche, doch hat es (selbst bei gelegentlichem Regen) viel Spaß gemacht und waren alle mit dem Ergebnis zufrieden. Bei vielen Passanten konnte durch diese Aktion das Interesse für den Palmengarten geweckt oder intensiviert werden.

Auch bei den Besucherinnen und Besuchern ist das Festival gut angekommen und es wurde gern für einen guten Zweck gespendet. Die Spenden kommen dem Verein Doctor Clowns e. V. zugute. Beim nächsten Grüne Soße Festival 2012 wird der Palmengarten wieder dabei sein.
Abb. 1 (Seite 158) : Der Palmengarten und die Gesellschaft stehen mit Rat und Tat zur Verfügung.

Abb. 2 (links): Großer Andrang beim Eintopfen.

Abb. 3 (rechts): Informationsmaterial verschiedenster Art wird angeboten. 